\title{
AMÉRICA EN LA LIBRERÍA DE DON LORENZO RAMÍREZ DE PRADO, CONSEJERO DE INDIAS ${ }^{1}$
}

\author{
Nieves Pena Sueiro \\ Universidade da Coruña \\ npena@udc.es \\ www.bidiso.es
}

RESUMEN / ABSTRACT

El estudio de inventarios de bibliotecas del Siglo de Oro resulta de gran importancia para aquellos que se interesan por la cultura áurea, pues desvela datos sobre sus poseedores; también sobre lecturas, obras, ejemplares, etc., que de otra manera no podríamos conocer. Una de las bibliotecas más importantes del siglo XVII fue la de don Lorenzo Ramírez de Prado, erudito y bibliófilo, que reunió en su casa madrileña por lo menos unos 8.951 volúmenes. Quizás la especial relación que tuvo don Lorenzo con América a lo largo de su vida -fue ahijado del humanista Pedro de Valencia, cronista de Indias; fue Consejero de Indias desde 1626 hasta su muerte, como también lo fue su hermano Alonso; otro de sus hermanos, Marcos, fue obispo de Michoacán, etc.-, influyó en que entre los fondos de su biblioteca se encuentren las principales obras de tema americano y algunas editadas en el Nuevo Mundo. En este trabajo pretendemos, tras el examen exhaustivo del inventario, ofrecer una relación de los registros del fondo americano (tema americano y obras impresas en América) que existían en la librería en el momento en que se inventarió, seguido del análisis y las conclusiones de este.

Palabras Clave: inventarios, bibliotecas, Lorenzo Ramírez de Prado, América.

The study of library inventories of the Golden Age is of great interest to those who study the culture of this period, as it reveals much about their owners, and also about readings, plays, copies, etc. about which otherwise we would not know.

1 Este trabajo se inscribe en el proyecto de investigación Biblioteca digital. Siglo de Oro IV (código FFI2012-3436) financiado por el Ministerio de Economía y Competitividad del Gobierno de España, en el marco del VI Plan Nacional de I+D+i 2008-2011. 
One of the most important libraries of the seventeenth century was that of Don Lorenzo Ramirez de Prado, erudite and bibliophile, who collected in his Madrid home at least 8,951 volumes. Don Lorenzo was godson of the humanist Pedro de Valencia, chronicler of the Indies, he was Counselor of the Indies from 1626 until his death, as was his brother Alonso; another brother, Marcos, was Bishop of Michoacan. Perhaps the special relationship that Don Lorenzo had with America throughout his life was the reason that among the volumes of his library are the major works on the subject of the Americas, some of them published in the New World. In the present paper, after a thorough examination of the inventory, we strive to provide a list of records about the subject of America or printed in America that were in the library at the time it was inventoried, followed by analysis and conclusions.

KEY WORDS: Inventories, Libraries, America, Lorenzo Ramírez de Prado.

Una de las figuras de gran relevancia en la vida política y cultural de los reinados de Felipe III y Felipe IV fue don Lorenzo Ramírez de Prado ${ }^{2}$. Formado en leyes en Salamanca bajo el magisterio de Sánchez de las Brozas, se mostró muy inclinado a las bellas letras, convirtiéndose en un distinguido erudito y bibliófilo. Mantuvo contacto con los círculos y academias poéticas madrileñas, escribió más de una veintena de obras filológicas, históricas y políticas y fue, también, editor de otras obras de gran relevancia, como los Sucesos principales de la monarquía de España en el año de 1639 de Virgilio Malvezzi ${ }^{3}$. Su dedicación humanista, su gran interés por el mundo de los libros y su labor como mecenas llenaron de alusiones a su talento, capacidades y oficios en las dedicatorias y demás preliminares de los impresos coetáneos, como puede leerse en este: "Al señor don Lorenzo Ramírez de Prado, dignísimo consejero del Rey de las Españas, diserto embajador destacado en Francia por el mismo, asaz avezado gracias a la gran agudeza de su talento y al vigor de su memoria en las dos ramas del Derecho y demás Bellas Letras..." (Francisco de Araoz 103)4.

Precisamente, gracias a la lectura de estos paratextos podemos resumir en unas líneas la gran cantidad de cargos que ocupó a lo largo de su vida: fue

2 No podemos detenernos en detallar aquí la interesante biografía de don Lorenzo, que ya ha sido trazada por varios investigadores (García Hernán 2002; Solís de los Santos 2012, etc.).

Autor que alcanzó extraordinaria difusión (como ha demostrado Simón Díaz 1965).

Cito por la edición de José L. Solís de los Santos. El ingenioso bibliólogo don Francisco de Araoz. Sevilla: Servicio de Publicaciones, 1997. 
miembro del Consejo del Rey, de Hacienda, de Estado, de Indias, de Nápoles, embajador de Francia, caballero de la Orden de Santiago, etc.

El gusto por el coleccionismo y por los libros -según parece heredado de su padre, don Alonso Ramírez de Prado, que llegó a reunir una biblioteca de 402 impresos y 24 manuscritos- le llevó a formar una de las bibliotecas más destacadas de la España del siglo XVII. Situada en su casa de la calle del Arenal en Madrid, la biblioteca de don Lorenzo Ramírez de Prado fue considerada entonces, y lo sigue siendo en la actualidad, como una de las más representativas del Siglo de Oro español, no solo por la cantidad de volúmenes que albergaba -8.951 "cuerpos" según el inventario realizado tras su muerte ${ }^{5}$ - sino también por la variedad de materias, la calidad de sus obras y ediciones y la riqueza de los ejemplares que se disponían en sus estantes.

La lectura de textos de la época nos permite constatar que era notoria la magnificencia de la biblioteca - a la que, según parece, no fue fácil el acceso y quienes pudieron disfrutarla solían mostrarse muy agradecidos ${ }^{6}-$. Con respecto a su contenido, no solo era excelente en cuanto a libros (y solo con ojear el inventario se comprueba) sino también por el valor "papeles" manuscritos

Llegó a tal desparaje la profusión y desbarato de los papeles más importantes de la monarquía y su reservado gobierno que se hizo negociación de ellos por parte de los extranjeros para hacerse ricos con ellos... Sea prueba de esta verdad, que por real Decreto de 16 de septiembre de 1664, dirigido al Presidente del Consejo, expresó

\footnotetext{
En 1658, tras fallecer don Lorenzo, su viuda decidió vender la voluminosa biblioteca de su marido, pero, debido a que había algunos libros prohibidos o expurgables (Ramírez de Prado tenía permiso expreso del Papa que le permitía el acceso a estas obras), fue necesario someterla a un examen por parte de la Inquisición antes de que pudiera ponerse a la venta, que no pudo llevarse a cabo hasta 1662. En el proceso de inventariado de la biblioteca con vistas a su venta, doña Lorenza de Cárdenas, su viuda, decidió imprimir un catálogo de la misma, editado por Entrambasaguas (1943), que solo parece recoger los impresos. Tras algunas indagaciones, todo indica que muchos de sus manuscritos se incorporaron al fondo del Colegio de Cuenca y ahora se conservan en la Biblioteca de la Universidad de Salamanca en su mayor parte (como por ejemplo un autógrafo de Libro de la Cámara Real de Gonzalo Fernández de Oviedo). En cuanto a los impresos, parece que al menos algunos pueden encontrarse también en Salamanca, aunque también en otras bibliotecas como la Real Biblioteca (Palacio Real de Madrid).
}

Francisco de Araoz le agradece "la gracia que me procuró vuestra merced, excelentísimo señor, de visitar vuestra colmadísima y muy selecta biblioteca...”(103), en el prólogo a su opúsculo, en el que le ofrece un original sistema de ordenación bibliográfica. 
S. M. había entendido estaba ajustado vender á un extranjero la librería de Don Lorenzo Ramírez de Prado, con todos los papeles manuscritos, en los cuales se juzgaba había muchos secretos, y de importancia; así del tiempo que asistió en Francia, como á otros negocios particulares que se le encargaron, y algunos que adquiría por curiosidad. Y conviniendo no pasasen á otras manos, ordenó S. $\mathrm{M}$. que con la mayor diligencia y recato se recogiesen todos en parte segura, y se formase relación de ellos, para remitirla á sus reales manos (Valladares de Sotomayor 1789).

Aunque algunos estudiosos han tratado ya sobre el contenido y disposición de esta biblioteca (Entrambasaguas, Rodríguez Moñino, Dadson, etc.), quizás no se ha incidido suficiente en uno de los aspectos singulares de esta librería: la presencia de América (temas, autores, obras impresas en el Nuevo Mundo, etc. $)^{7}$. Nuestro propósito en este trabajo, tras un análisis exhaustivo del inventario, es, precisamente, señalar esta particularidad y ofrecer la relación de registros del fondo americanista de la biblioteca acompañada de unas conclusiones, resultado del análisis, tanto del número de obras y su temática, como del conocimiento que podía tener un consejero de Indias sobre estas tierras, sus costumbres y su gente, aún sin haber viajado nunca allí.

Antes de proseguir, no puede dejar de advertirse que la presencia de fondos sobre el Nuevo Mundo en la librería de don Lorenzo no es casual, pues varios acontecimientos familiares y profesionales lo relacionaron con América desde su nacimiento. El humanista Pedro de Valencia, cronista de Indias, que era primo de su padre, lo apadrinó al poco de nacer (en 1583). Don Alonso Ramírez de Prado, padre de don Lorenzo, fue Consejero (Oidor) del Consejo Real y Supremo de las Indias ${ }^{8}$. Don Lorenzo fue nombrado miembro

Trevor J. Dadson (1993-94) estudió hace tiempo la presencia de libros sobre el Nuevo Mundo (incluyendo las Indias Occidentales y Orientales) en 67 bibliotecas privadas. En la biblioteca Ramírez de Prado localizó 126 ejemplares, aun advirtiendo que por ser un inventario muy largo podría no haber sido un recuento exacto. Para más información, vid. Schäfer.

El Real y Supremo Consejo de Indias fue el órgano más importante de la administración indiana pues asesoraba al rey en la función ejecutiva, legislativa y judicial. Se creó en 1511 como una sección dentro del Consejo de Castilla, y luego, en 1524, pasa a constituirse como entidad propia. Los Consejeros de Indias eran normalmente elegidos entre personas de gran versación jurídica y eruditos en temas americanos, la gran mayoría eran hombres con experiencia funcionaria en las Indias, aunque poco a poco el sistema de privanzas que se impone en el siglo XVII hace que reduzca su eficacia, el número de miembros crece significativamente, dando 
del Consejo de Indias en 1626, cargo que ocupó durante 32 años, hasta su muerte en $1658^{9}$, como también fue su hermano Alonso hasta su muerte en $1664^{10}$, llegando a ser decano del tal Consejo. Otro de sus hermanos, Marcos Ramírez de Prado, fue obispo de Chiapas, Michoacán -donde contribuyó a la restauración de la catedral de Valladolid con la ayuda de los Consejeros de Indias- y, más tarde, arzobispo de México (aunque falleció antes de desempeñar este oficio). Y, además de todo esto, don Lorenzo dotó a su mujer, doña Lorenza de Cárdenas, con una encomienda en Indias.

Es, por lo tanto, bastante evidente que a su curiosidad natural, las circunstancias personales y profesionales hicieron que se desarrollase en él un interés especial por el tema americano, y no es coincidencia que en la biblioteca de don Lorenzo se encuentren obras fundamentales sobre las Indias occidentales ${ }^{11}$.

En el trabajo que nos ocupa pretendemos ofrecer una relación completa del fondo americano (obras sobre América o publicadas allí), que el humanista poseyó que nos permitan extraer conclusiones acerca del interés que despertaba el Nuevo Mundo y el conocimiento que podía tener un erudito del siglo XVII, consejero de Indias, aun cuando no hubiese cruzado el Atlántico. A propósito de esto, resultan válidas para esta librería las palabras de P. Cátedra al referirse a la colección americana de la biblioteca de otro ilustre bibliófilo, don Alonso de Osorio, marqués de Astorga: "la colección americana de Osorio, prácticamente formada antes de 1574 , por cuanto apenas se añaden títulos después, es muy buena y muestra que no se puede afirmar, como a veces se ha hecho, que haya un desinterés por incorporar a las bibliotecas asuntos americanos" (Cátedra García 227). Efectivamente, también la curiosidad de erudito, el interés de bibliófilo y las circunstancias, como hemos señalado, suponen que la librería de Ramírez de Prado sea una muestra, todavía más clara, de la sensibilidad hacia el tema.

cabida a nuevos oficiales e incluyéndose consejeros de capa y espada. Para más información, vid Schäfer.

9 Las huellas de su labor pueden seguirse en el Archivo de Indias, e indican que este cargo no fue uno más en su larga lista de "oficios".

10 Sobre ambos, inserta una larga alabanza Lope de Vega en su Laurel de Apolo: “dos ínclitos varones / dos Prados, dos hermanos, dos Catones ...".

11 Trevor Dadson (1992) contabilizó 106 relativas a las Indias occidentales en el inventario de su librería. 
Tras la lectura detenida y el estudio del inventario -teniendo en cuenta las limitaciones que estos suelen ofrecer (Infantes 281-292) - y gracias a las posibilidades de análisis que nos brindan las bases de datos ${ }^{12}$ que permiten cruzar información de manera ágil, flexible y rápida, hemos obtenido resultados sobre la investigación en el tema que nos ocupa que ofrecemos a continuación:

Como ya se ha señalado, según el inventario, la librería se compone de 8.951 "cuerpos". Entre las ausencias que más se dejan notar están los impresos menores y los manuscritos; es probable que algunos formen parte de los más de 200 que el doctor don Esteban de Aguilar y Zúñiga -el sacerdote que se ocupó de expurgar las obras conforme al Índice de libros prohibidos y redactó el inventario-, el librero Baltasar Velero y algunos amigos se llevaron, según denuncia la viuda de Ramírez de Prado. Si tenemos en cuenta estos datos, podemos advertir que es posible que el número de ejemplares de esta librería llegase, por lo menos, a los 9.200 volúmenes.

De los 8.951 cuerpos inventariados, 136 hacen referencia a América. Su contenido es variado, abarcando los temas más diversos: conquista, historia natural, crónicas, leyes, informaciones y consultas, lengua, prodigios, autos de fe, fiestas, etc. En la biblioteca hubo, pues, buena representación de los asuntos de Indias (puede consultarse al final la relación de títulos, extraída del inventario): las obras esenciales, que surgen como consecuencia de los cambios que supone el conocimiento del Nuevo Mundo -legislativos, intelectuales, científicos, etc.- están casi todas. La más antigua de las inventariadas es un ejemplar de la obra de Martín Fernández de Enciso, Suma de geographia que trata de todas las partidas y provincias del mundo en especial de las Indias, publicada en Sevilla en 1519; le sigue un ejemplar de la obra de Pedro Mártir de Anglería, De orbe novo ${ }^{13}$, publicada en Alcalá, por Miguel

12 Me refiero, especialmente, a la base de datos de Inventarios y Bibliotecas del Siglo de Oro, IBSO, <http:www.bidiso.es/IBSO>, integrada ahora en el portal Biblioteca Digital Siglo de Oro, que ha creado y mantiene equipo de investigación de la Universidad de A Coruña formado por Sagrario López Poza. El principal objetivo de esta base de datos es reunir y poner al alcance de los investigadores el resultado de varios tipos de trabajos que frecuentemente se encuentran dispersos; IBSO permite el acopio y la recuperación y consulta cruzada de información en torno a cuatro vías: inventarios y bibliotecas, bibliotecas ideales, bibliotecas hipotéticas, ediciones del Siglo de Oro (puede obtenerse más información, sobre sus funcionalidades y contenido en Fernández Travieso y López Poza 1-30).

13 Obra realizada por encargo de la reina Isabel la Católica para la elaboración de las crónicas sobre la aventura oceánica. En el inventario aparece sin datos de edición, solo el título, por lo que no puede certificarse que se trate de la primera. 
de Eguía en 1530. Entre las piezas más famosas de su colección está una de las dos versiones manuscritas de la Historia del Pirú de Martín de Murúa ${ }^{14}$, o La historia verdadera de la conquista de nueva España por Hernán Cortés de Bernal Díaz del Castillo, que permaneció inédita mucho tiempo hasta que fray Alonso Remón la publicó en 1632. Otra presencia notable es la obra de fray Bartolomé de las Casas, tanto su Apologética historia de las gentes de estas Indias, en primera edición de Sevilla, 1552, como su Historia de la destruyción de las Indias, en este caso en edición veneciana, en español e italiano, de $1630^{15}$; también está la obra del que sería su opositor, J. Ginés de Sepúlveda, De conuenientia militaris disciplinae cu[m] christiana religione dialog[us], qui inscribitur Democrates, publicada en Roma, en 1535. No podían faltar otras obras como la Crónica del Perú, de Pedro Cieza de León, en dos ediciones, Sevilla, 1553 (editio princeps) y Amberes, 1554; Francisco López de Gómara, en su edición de $1554^{16}$ (aunque solo la 2a parte); Gonzalo Férnandez de Oviedo, Historia general de las Indias, Sevilla, 154777; la Relación del Gouernador Aluar Núñez, de dos viages de las Indias, impresa en Valladolid por Francisco Fernández de Córdoba, en 1555 (en editio princeps); José Acosta, De natura novi orbis, Salmanca, Guillelmum Foquel, 1589, (editio princeps) y, en segunda edición, la Historia natural, y moral

14 Es sabido que Fray Martín Murúa ofreció esta versión como regalo a Felipe IV en 1616; sin embargo, este ejemplar acabó en la librería de Lorenzo Ramírez de Prado.

15 Istoria ó breuissima relatione della distruttione dell' Indie Occidentali di Don Bartolomeo dalle Case ó Casaus conforme al suo vero originale spagnuolo già stampato in Siuiglia tradotta in italiano dall' sig. Giacomo Castellani già sotto nome di Francesco Bersabita ..., In Venetia: presso Marco Ginammi, 1630. Podemos ver un ejemplar de esta edición, ya accesible en Internet, en la Biblioteca Digital Hispánica http://bdh.bne.es/bnesearch/ detalle/2683725

16 Suponemos que será la edición impresa en Zaragoza por Pedro Bernuz el 12 de octubre de 1554 (en portada 1555, véndese en casa de Miguel de Çapila), profusamente ilustrada, de la que hoy se conserva un ejemplar, en la Biblioteca del Dr. Francisco Guerra, en la biblioteca histórica de la Universidad Complutense de Madrid (Fernández Valladares $6)$.

17 Aunque no tenemos otra noticia de esta edición [ni en CCPB, ni en otros catálogos], así que, o bien se trata de una edición perdida o puede que, simplemente, sea un error de quien hizo o compuso en la imprenta este inventario. La única edición documentada de esta obra en este año es la de Salamanca, en casa de Juan de Junta, 1547, con ilustraciones xilográficas intercaladas en el texto [Simón Díaz. BLH, Tomo X, n. 1102]. 
de Indias, Barcelona, 1591; o un ejemplar de los Varones ilustres de Indias, de Juan de Castellanos, Madrid, $1589^{18}$.

También las obras sobre el Nuevo Mundo que tuvieron más repercusión en el siglo XVII están en el inventario de la librería de Ramírez de Prado. Así, podrían destacarse varias ediciones de Historia general de los hechos de los castellanos en las Indias, de Antonio de Herrera, Madrid, 1601 y Valladolid, 1606 y también de su Descriptio Indiae Occidentalis, ab Antonio de Herrera, in Latinum, versa a C. Barlzo, cum pluribus, additionibus, \& Mappis ${ }^{19}$; los Comentarios reales, del Inca Garcilaso de la Vega, en su primera edición de Lisboa, 1609; el Tratado de confirmaciones Reales de oficios de Indias, Madrid, Juan González, 1630, que, según parece, fue encargado por el propio don Lorenzo a Antonio de León Pinelo, cronista Oficial de Indias; o la Histórica relación del Reyno de Chile, de Ovalle Santarém, publicada en Roma, por Francisco Cavallo en 1648. No puede dejar de notarse que, según pasan los años, el número de obras de tema americano en la librería de don Lorenzo aumenta, como puede comprobarse en el anexo III (lám. 1).

Mención especial merecen las obras de cosmografía, geografía, mapas, atlas... Destacan: la Suma de geographia de Martínez de Enciso - una de la primeras que incluye América-con ejemplar de la edición prínceps sevillana, de 1519; la Cosmographía de Pedro Apiano, en romance, Amberes, en casa de Gregorio Bontio, 1548, del que parece poseer, según se desprende del inventario, dos ejemplares de esta edición, otro de una edición de 1575, también en romance, y una edición en latín de $1549^{20}$; cuatro ediciones de Ortelius, Theatrum Orbis Terrarum, (de $1579^{21}$ en la que ya se incluían mapas de América, de Amberes, 1588, y otras dos de 1624 y 1630). de don Lorenzo, poseyó la cuarta parte de esta obra, y que es probable que don Lorenzo la heredase.

19 No hay referencias en el inventario a su lugar de edición, por lo que puede que en la biblioteca se conservase un manuscrito de esta obra o que se trate del Novvs orbis sive descriptio Indiae Occidentalis, publicado en Amstelodami, Michael Colinivs, 1622.

20 Aunque la obra se editó por primera vez en 1525 y con las correcciones de Gemma Frissio en 1529, contó con varias reediciones: hasta la edición de 1544 no aparece Méjico en el mapa mundi de la Cosmografía.

$21 \quad$ En el inventario indica "illuminatum". 


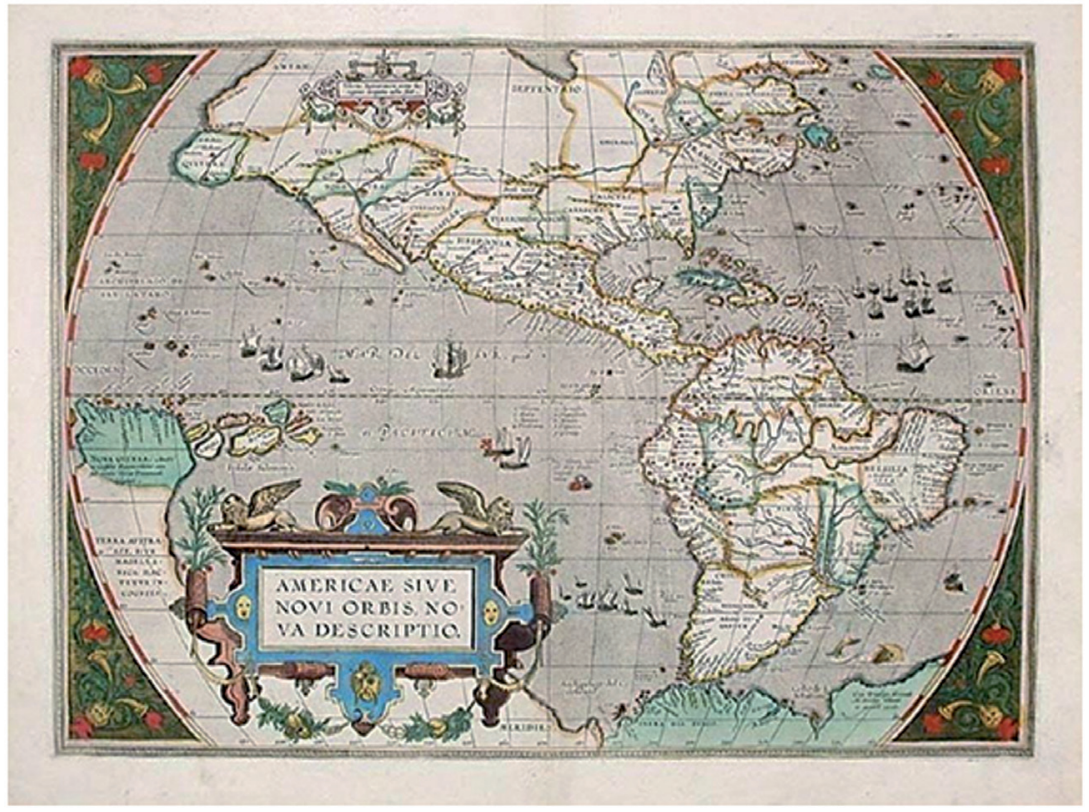

Lámina 1: Abraham Ortelius, Americae sive Novi Orbis.

No falta la obra que relata el viaje de los hermanos García de Nodal a reconocer el estrecho de Magallanes, Relación del viaje que por orden de su Majestady acuerdo del Real Consejo de Indias hicieron los capitanes Bartolomé García de Nodal y Gonzalo de Nodal, hermanos... al descubrimiento del Estrecho nuevo de S. Vicente y reconocimiento del de Magallanes, en Madrid, por Fernando Correa de Montenegro, 1621.

En lo que se refiere a los libros jurídicos sobre el tema, el inventario registra, además de la obra de León Pinelo a la que se ha aludido antes, títulos tan notables como De indianarum iure, Madrid, 1629, de Juan de Solórzano, que se convirtió en libro de cabecera de los que ejercían el gobierno de Indias, labor que prosiguió en un segundo volumen (también registrado en la librería) publicado en Madrid en1639, así como unas observaciones a su obra, que hizo Antonio Lelio, publicadas en Roma en 1641. También poseyó la versión castellana de la extensa obra de Solórzano, que apareció en 1647 con el título de Política Indiana (obra fundamental para conocer el siglo XVII en la América española) y que fue algo más que mera traducción, pues modificó, amplió y seccionó varias partes de la obra anterior. 
Algunos asientos del inventario muestran libros de informaciones de Indias que recuerdan las ocupaciones y quehaceres como miembro del Consejo de Indias de don Lorenzo: Un libro de informaciones de Indias, tocante a justicia; Un libro de informaciones de visitas en las Indias; Un libro de informaciones de Indias, todas Fiscales; Vn libro de informaciones de Indias, en materia de marauedis, etc. También se registran obras de interés filológico como: Tesoro de la lengua guaraní, Gramática de la lengua del Perú, por Diego Gonzalez Holguín, Lima, 1607, o la Gramática de la lengua del Nueuo Reyno, por Fr. Bernardo de Lugo, Madrid, 1619, etc.

Entre las obras de creación que sugiere América, no puede olvidarse que en los estantes de esta biblioteca figuraban, entre otras, El Mundo Nueuo, de Tomaso Stigliani, publicado en Roma en 1628, en su versión final de 34 cantos, dedicado al papa Alejandro VII y anotado por Pompeyo Colonna, que es una trasposición épica de la empresa colombina. Tampoco falta el gran poema épico, La Araucana de Alonso de Ercilla, en edición de Madrid, en la imprenta del Reino, 1632.

No solo la cultura clásica y lo atemporal tuvo asiento en la erudita biblioteca de don Lorenzo, también se registran varios impresos que dejan constancia de fiestas y otros acontecimientos circunstanciales en el Nuevo Mundo: Fiestas de México al Conde de Salvatierra y al Marqués de Villena y Obispo Palafox; Auto de Fe en México, 1649; Exequias de la Reyna Margarita en Perú, Lima, 1612; Relación del Martirio de unos jesuitas, en Paraguay, año 1628, etc.

Sin embargo, son llamativas las ausencias de algunas obras esenciales sobre el tema ${ }^{22}$ como las cartas de Colón o las de Hernán Cortés, de las que es probable que don Lorenzo poseyese algún ejemplar, impreso o manuscrito, que no llegó a ser inventariado, quizás por quedárselo algún familiar, quien hizo el inventario, o venderse aparte.

$22 \quad Y$ otras que no vienen aquí al caso por no tratar del tema que nos ocupa, obras de divertimento, como las primeras ediciones de El Quijote, por ejemplo, que es extraño que no poseyese, en el inventario solo figura: "D. Quixote de Ceruantes I y 2 en vn tomo, Madrid 1655 " y "Nouelas de Ceruantes, Madrid 1655"; tampoco libros de caballerías, la Diana, o el Guzmán de Alfarache... obras que sí están en inventarios de otras bibliotecas contemporáneas, como la del conde de Gondomar o la de Vincencio Juan de Lastanossa. 
En definitiva, según el inventario de la librería de don Lorenzo Ramírez de Prado, un 1,50 \% del total de las obras (137) trataban sobre América o se imprimieron en el Nuevo Mundo ${ }^{23}$ (25 impresos: 14 en México y 11 en Lima).

La rica biblioteca de Ramírez de Prado, en lo referente a América, puede decirse que presenta un panorama nutrido de lo que se escribía y publicaba en el momento y ofrecía información útil para quien quisiese documentarse sobre cualquier aspecto relacionado con el Nuevo Mundo: geografía, costumbres, historia natural, jurisdicción, medicina, fiestas, etc. Como dato curioso, debe tenerse en cuenta que, según el inventario (y aunque muchas obras se registran sine notis), apenas hay año del que no se registre, por lo menos, un libro impreso. De entre los títulos que presentan datos de edición, los lugares de impresión más frecuentes de las obras de tema americanos son Madrid, México, Lima, Sevilla.

Entre los autores están presentes los fundamentales de la historiografía americana: Anglería, Fernández de Oviedo, Acosta, Bartolomé de las Casas, Ginés de Sepúlveda, P. Cieza, Monardes, Herrera, Garcilaso, León Pinelo, etc. No debe olvidarse, además, que la librería estuvo también nutrida de papeles anónimos, colecciones de ordenanzas de Indias, acuerdos del Consejo de Indias, mapas, etc.

Estas conclusiones, aunque se basan en datos empíricos, han de considerarse con cautela, pues, como ya se ha señalado en ocasiones los inventarios revelan tanto las ausencias como las presencias en las librerías. Como advierte S. López Poza (19-48): "Trabajar con inventarios para intentar hacerse una idea de la realidad de una época tan lejana requiere mucha prudencia, pues podemos creer relevantes algunos datos presentes, pero no juzgamos otros ausentes de tanta o mayor importancia". A la vista de estos datos, es evidente en el inventario que don Lorenzo Ramírez de Prado estaba muy documentado sobre el Nuevo Mundo y, como Consejero de Indias, poseía una nutrida librería profesional, además de piezas de experto bibliófilo y coleccionista. Parece claro en el siglo XVII que ser Consejero de Indias requería estar bien informado y conocer, por lo menos, lo que se había escrito sobre el tema. Por otra parte, es evidente que la suma de la afición bibliofílica de don Lorenzo y el cargo de Consejero de Indias tuvieron mucho que ver en la conformación de su librería y su colección americanista.

23 Pero, ténganse en cuenta que estos impresos no trataron siempre de temas americanos, (vid., por ejemplo, la Ortografía de la lengua castellana, escrita por Mateo Alemán). 


\section{ANEXO I-AMÉRICA EN LA BIBLIOTECA DE DON LORENZO RAMÍREZ DE PRADO (obras sobre América o impresas en el Nuevo Mundo) ${ }^{24}$}

\begin{tabular}{|c|c|c|c|}
\hline & Título & $\begin{array}{l}\text { Lugar de } \\
\text { publicación }\end{array}$ & $\begin{array}{l}\text { Fecha de } \\
\text { publica- } \\
\text { ción }\end{array}$ \\
\hline 1. & $\begin{array}{l}\text { Exequias del Príncipe D. Balthasar, en Nueua } \\
\text { España, quatro duplicados }\end{array}$ & & \\
\hline 2. & Palafox, Semana Santa & México & 1644 \\
\hline 3. & Palafox, Varón de deseos & México & 1642 \\
\hline 4. & Confessión en lengua mexicana & México & 1565 \\
\hline 5. & D. Iuan María de Gueuara, Corona de la Virgen & Lima & 1643 \\
\hline 6. & Discurso breue contra los Indios, en Portugués & Lisboa & 1622 \\
\hline 7. & $\begin{array}{l}\text { Doctrina Christiana, en lengua Mystica, por Fr. } \\
\text { Benito Hernández }\end{array}$ & México & 1568 \\
\hline 8. & $\begin{array}{l}\text { Symbolo Cathólico Indiano, por Fr. Gerónimo de } \\
\text { Ore }\end{array}$ & Lima & 1598 \\
\hline 9. & $\begin{array}{l}\text { Fr. Iuan Baptista, Aduertencias a Confessores, } 2 \\
\text { part. }\end{array}$ & México & 1600 \\
\hline 10. & Felicianus de Vega, Relect. in 2 decreti & Lima & 1633 \\
\hline 11. & Additiones Ludouici de Lima & Lima & 1634 \\
\hline 12. & Ordenanças del Consejo de Indias & Valladolid & 1603 \\
\hline 13. & $\begin{array}{l}\text { Antonio de León, tratado de confirmaciones } \\
\text { Reales para oficios, y encomiendas de Indias }\end{array}$ & Madrid & 1630 \\
\hline 14. & $\begin{array}{l}\text { Discursos sobre los priuilegios de las órdenes de } \\
\text { Indias, por Don Iuan Ceuicos }\end{array}$ & México & 1623 \\
\hline 15. & $\begin{array}{l}\text { Memorial sobre la protección de los Indios del } \\
\text { Perú }\end{array}$ & Madrid & 1636 \\
\hline 16. & $\begin{array}{l}\text { Memorial sobre la protección de los Indios del } \\
\text { Perú }\end{array}$ & Madrid & 1636 \\
\hline 17. & Escrito en la causa de la Puebla de los Ángeles & & 0 \\
\hline
\end{tabular}

24 Se han respetado las grafías y el orden del inventario, pues nos permite vislumbrar, en ocasiones, la existencia de varios ejemplares y, posiblemente, la disposición de la librería. 


\begin{tabular}{|c|c|c|c|}
\hline 18. & $\begin{array}{l}\text { Planeta Cathólico, o Memorial, para que el Rey } \\
\text { embíe Predicadores a las Prouincias del Perú, de } \\
\text { Fr. Balthasar Campuçano }\end{array}$ & Madrid & 1646 \\
\hline 19. & $\begin{array}{l}\text { Memorial de la Compañía de Iesús de Nueua } \\
\text { España, en respuesta de Palafox }\end{array}$ & & \\
\hline 20. & $\begin{array}{l}\text { Razonamiento al Conde de Castrilo, en fauor del } \\
\text { Colegio de S. Felipe de Lima }\end{array}$ & Madrid & 1633 \\
\hline 21. & $\begin{array}{l}\text { Estado de las Filipinas, y sus conueniencias, por } \\
\text { D. Gerónimo Bañuelos }\end{array}$ & México & 1638 \\
\hline 22. & $\begin{array}{l}\text { Apol. de Fr. Barthol. de las Casas, por los Indios. } \\
\text { Otro. }\end{array}$ & Sevilla & 1552 \\
\hline 23. & Ordenanças de las Indias, 4 tom. & Madrid & 1596 \\
\hline 24. & $\begin{array}{l}\text { Sumario de todas las leyes, y ordenanças de las } \\
\text { Indias por Don Rodrigo de Aguiar }\end{array}$ & Madrid & 1628 \\
\hline 25. & $\begin{array}{l}\text { Discurso sobre la importancia de las leyes de } \\
\text { Indias, por el Licenciado León }\end{array}$ & & \\
\hline 26. & $\begin{array}{l}\text { Acuerdos del Consejo de Indias, recopiladas por } \\
\text { Don Antonio de León }\end{array}$ & Madrid & 1658 \\
\hline 27. & Ordenanças del Consejo de Indias & Madrid & 1636 \\
\hline 28. & $\begin{array}{l}\text { Aparato Político de las Indias, Don Antonio de } \\
\text { León }\end{array}$ & Madrid & 1635 \\
\hline 29. & $\begin{array}{l}\text { Perfecta razón de Estado, contra Polit. Atheit. por } \\
\text { Don Iuan Básquez Mayoralgo }\end{array}$ & México & 1646 \\
\hline 30. & $\begin{array}{l}\text { Duarte Gómez, sobre los comercios e las dos } \\
\text { Indias }\end{array}$ & & 1622 \\
\hline 31. & $\begin{array}{l}\text { Antonio de León, tratado de confirmaciones } \\
\text { Reales de oficios de Indias }\end{array}$ & Madrid & 1630 \\
\hline 32. & $\begin{array}{l}\text { Relación de los Obispados de España, y Indias, } \\
\text { por Alberto Mireo; y otra en Latín de las reglas } \\
\text { Monásticas; y otra de los Obispados de Italia }\end{array}$ & Amberes & 1613 \\
\hline 33. & $\begin{array}{l}\text { Ordenanças del Obispado de Mechoacan, por D. } \\
\text { Fr. Marcos Ramírez }\end{array}$ & México & 1645 \\
\hline 34. & $\begin{array}{l}\text { Vn libro de informaciones de la Cruzada, tocante } \\
\text { a Indias }\end{array}$ & & \\
\hline 35. & $\begin{array}{l}\text { Veinte y tres informaciones tocantes a materias de } \\
\text { Indias }\end{array}$ & & \\
\hline 36. & Ordenanças del Consejo de Indias & Valladolid & 1603 \\
\hline
\end{tabular}




\begin{tabular}{|c|c|c|c|}
\hline 37. & Varios papeles tocantes a cosas de Indias & & \\
\hline 38. & Cosas tocantes al Reyno de Chile & & \\
\hline 39. & $\begin{array}{l}\text { Vn libro de informaciones de Indias, tocante a } \\
\text { justicia }\end{array}$ & & \\
\hline 40. & $\begin{array}{l}\text { Otro libro de informaciones de Indias, tocante a } \\
\text { justicia }\end{array}$ & & \\
\hline 41. & Vn libro de informaciones de visitas en las Indias & & \\
\hline 42. & $\begin{array}{l}\text { Vn libro de informaciones de Indias, todas } \\
\text { Fiscales }\end{array}$ & & \\
\hline 43. & $\begin{array}{l}\text { Vn libro de informaciones de Indias, en materia } \\
\text { de marauedís }\end{array}$ & & \\
\hline 44. & $\begin{array}{l}\text { Otro libro de informaciones de Indias, todas } \\
\text { Fiscales }\end{array}$ & & \\
\hline 45. & $\begin{array}{l}\text { Otro libro de informaciones de Indias, todas } \\
\text { Fiscales }\end{array}$ & & \\
\hline 46. & $\begin{array}{l}\text { Otro libro de informaciones de Indias, todas } \\
\text { Fiscales }\end{array}$ & & \\
\hline 47. & $\begin{array}{l}\text { Otro libro de informaciones de Indias, todas } \\
\text { Fiscales }\end{array}$ & & \\
\hline 48. & $\begin{array}{l}\text { Mapas del Puerto de la Habana, y Isla de Santo } \\
\text { Domingo }\end{array}$ & & \\
\hline 49. & $\begin{array}{l}\text { Gramática de la lengua del Perú, por Diego } \\
\text { Gonçález Holguin }\end{array}$ & Lima & 1607 \\
\hline 50. & $\begin{array}{l}\text { Gramática de la lengua del Perú, por Diego } \\
\text { Gonçález Holguin }\end{array}$ & Lima & 1607 \\
\hline 51. & Ortographía Castellana de Matheo Alemán & México & 1609 \\
\hline 52. & $\begin{array}{l}\text { Elegías de varones ilustres de Indias, por Iuan de } \\
\text { Castellanos }\end{array}$ & Madrid & 1589 \\
\hline 53. & $\begin{array}{l}\text { Fiestas de México al Conde de Saluatierra, y al } \\
\text { Marqués de Vullena, y Obispo Palafox, en vn } \\
\text { tomo }\end{array}$ & & \\
\hline 54. & La Nueua México de Villagra & Alcalá & 1610 \\
\hline 55. & $\begin{array}{l}\text { Abraham Hortel, Theatrum orbis, tres tomi, cum } \\
\text { Parergis, \& tabulis Geograph. Amstel. \& Ant. }\end{array}$ & $\begin{array}{l}\text { Amberes- } \\
\text { Ámsterdam }\end{array}$ & $1624-1630$ \\
\hline 56. & Abraham Hortelio, Theatro de la tierra & Amberes & 1588 \\
\hline
\end{tabular}




\begin{tabular}{|c|c|c|c|}
\hline 57. & Abraham Ortelij, Theatrum orbis & Amberes & 1579 \\
\hline 58. & $\begin{array}{l}\text { Doze Mapas iluminadas del Perú, todas en vn } \\
\text { quaderno }\end{array}$ & & \\
\hline 59. & $\begin{array}{l}\text { Regimiento de Nauegación, por orden del Consejo } \\
\text { de Indias, por Andrés García de Céspedes }\end{array}$ & Madrid & 1602 \\
\hline 60. & Summa Geographica, General, y especial, de Indias & Sevilla & 1519 \\
\hline 61. & $\begin{array}{l}\text { Repertorio de los tiempos de Nueua España, por } \\
\text { Henrico Martínez }\end{array}$ & México & 1606 \\
\hline 62. & $\begin{array}{l}\text { Repertorio de los tiempos de Nueua España, por } \\
\text { Henrico Martínez }\end{array}$ & México & 1606 \\
\hline 63. & Diálogos Militares de Diego García de Palacio & México & 1585 \\
\hline 64. & $\begin{array}{l}\text { Plantas, y animales de la Nueua España, y sus } \\
\text { virtudes, por Francisco Hernández, y de Latín en } \\
\text { Romance, por Fr. Francisco Ximénez }\end{array}$ & México & 1615 \\
\hline 65. & $\begin{array}{l}\text { Plantas, y animales de la Nueua España, y sus } \\
\text { virtudes, por Francisco Hernández, y de Latín en } \\
\text { Romance, por Fr. Francisco Ximénez }\end{array}$ & México & 1615 \\
\hline 66. & $\begin{array}{l}\text { Historia de Simplex, Aromáticos, y otras drogas } \\
\text { de Indias, que escriuió en Portugués Don García } \\
\text { de Huerta, en Italiano, por Aníual Briganti }\end{array}$ & Venecia & 1605 \\
\hline 67. & $\begin{array}{l}\text { Historia Medicinal de cosas de Indias, por } \\
\text { Monardes }\end{array}$ & Sevilla & 1580 \\
\hline 68. & $\begin{array}{l}\text { Aduertencias para beber frío de nieue, del Doctor } \\
\text { Matías de Porres }\end{array}$ & Lima & 1621 \\
\hline 69. & Historia Medicinal de las Indias, de Monardes & Sevilla & 1580 \\
\hline 70. & $\begin{array}{l}\text { El mismo Teatro de las Iglesias de Indias. Tres } \\
\text { Tomos, Primero, abaxo ay más }\end{array}$ & Madrid & 1649 \\
\hline 71. & $\begin{array}{l}\text { Historia Plantar. \& animalium Brasili, Guillelmi } \\
\text { Pisonis }\end{array}$ & Batau & 1648 \\
\hline 72. & $\begin{array}{l}\text { Teatro Eclesiástico de las Iglesias de Indias, por } \\
\text { Gil Gonçález Dáuila, dos tomos }\end{array}$ & Madrid & 1655 \\
\hline 73. & $\begin{array}{l}\text { Historia Peruana, Ordinis S. Agustini, à Ioachimo } \\
\text { Brulio }\end{array}$ & & 1651 \\
\hline 74. & $\begin{array}{l}\text { Chrónica moraliçada de la Orden de San Agustín, } \\
\text { en el Perú, por Fr. Antonio de la Calancha }\end{array}$ & Barcelona & 1639 \\
\hline 75. & $\begin{array}{l}\text { Chrónica de la misma Orden. en Nueua España } \\
\text { por Fray Iuan de Grijalua }\end{array}$ & México & 1624 \\
\hline
\end{tabular}




\begin{tabular}{|c|c|c|c|}
\hline 76. & $\begin{array}{l}\text { Chrónica de la misma Orden. en Nueua España } \\
\text { por Fray Iuan de Grijalua }\end{array}$ & México & 1624 \\
\hline 77. & $\begin{array}{l}\text { Andrés Pérez de Ribas, de las Missiones de la } \\
\text { Compañía en Nueua España }\end{array}$ & Madrid & 1645 \\
\hline 78. & $\begin{array}{l}\text { Relación Histórica del Reyno de Chile, por } \\
\text { Alonso de Oualle }\end{array}$ & Roma & 1648 \\
\hline 79. & $\begin{array}{l}\text { Petrus Martyr, Decades de Orbe nouo, liber } \\
\text { Acephales, \& Apodos }\end{array}$ & & \\
\hline 80. & Historia del Perú, por Diego Fernández Sevilla & & 1571 \\
\hline 81. & $\begin{array}{l}\text { D. Fernando Pizarro, Varones ilustres del nueuo } \\
\text { Mundo }\end{array}$ & Madrid & 1639 \\
\hline 82. & $\begin{array}{l}\text { Conquista de tierra firme en Indias Occidentales, } \\
\text { por Fray Pedro Simón }\end{array}$ & Cuenca & 1625 \\
\hline 83. & $\begin{array}{l}\text { Historia de la conquista de la Nueua España, por } \\
\text { el Capitán Bernal Díaz, y publicada por Fr. Alonso } \\
\text { Remón }\end{array}$ & Madrid & 1632 \\
\hline 84. & $\begin{array}{l}\text { Historia de las fundaciones de Dominicos en } \\
\text { México, por Fr. Agustín Dáuila Padilla }\end{array}$ & Bruselas & 1625 \\
\hline 85. & $\begin{array}{l}\text { Historia general de las Indias, de Gonçalo de } \\
\text { Vuiedo, y la conquista del Perú }\end{array}$ & Sevilla & 1547 \\
\hline 86. & Historia de las Indias, de Antonio de Herrera, 4 tomos & Madrid & 1601 \\
\hline 87. & $\begin{array}{l}\text { Historia general de las Indias, de Gonçalo de } \\
\text { Vuiedo, y la conquista del Perú }\end{array}$ & Sevilla & 1547 \\
\hline 88. & $\begin{array}{l}\text { Historiarum Americae admirandae narraciones, à } \\
\text { varijs Authoribus compilatae }\end{array}$ & & 1590 \\
\hline 89. & Hist. Antigua de las Indias, hasta el año de 1551 & $\begin{array}{l}\text { Medina del } \\
\text { Campo }\end{array}$ & 1553 \\
\hline 90. & Comentarios Reales del Perú, por Garcilaso, dos tom. & Lisboa & 1609 \\
\hline 91. & Historia del Perú, por Diego Fernández & Sevilla & 1571 \\
\hline 92. & Conquista del Perú & Salamanca & 1547 \\
\hline 93. & $\begin{array}{l}\text { Chrónica del Perú, de Pedro de Cieza, Primera } \\
\text { Parte }\end{array}$ & Sevilla & 1553 \\
\hline 94. & $\begin{array}{l}\text { Historia de la Prouincia de Sen Vicente de Chiapa, } \\
\text { y Guatemala del Orden Dominico, por Fr. Antonio } \\
\text { de Remesal }\end{array}$ & Madrid & 1619 \\
\hline & $\begin{array}{l}\text { Decimatertia pars historiae Americanae, Franc. ad } \\
\text { Maenum }\end{array}$ & & 1634 \\
\hline
\end{tabular}




\begin{tabular}{|c|c|c|c|}
\hline 96. & $\begin{array}{l}\text { Relación del sitio de México, y su desagüe, de } \\
\text { Don Fernando de Cepeda }\end{array}$ & & 1637 \\
\hline 97. & $\begin{array}{l}\text { Ioannes de Laet Americae, vnisque descriptio } \\
\text { Latinae, con estampas }\end{array}$ & Lugduni & 1633 \\
\hline 98. & $\begin{array}{l}\text { Viage del Marqués de Villena a Indias, con } \\
\text { poesías }\end{array}$ & & 1640 \\
\hline 99. & Auto de Fe & Lima & 1639 \\
\hline 100. & $\begin{array}{l}\text { Memorias diarias del Brasil, hasta el año de } 1630 . \\
\text { por Duarte de Albuquerque }\end{array}$ & Madrid & 1654 \\
\hline 101. & Auto de Fé & México & 1649 \\
\hline 102. & $\begin{array}{l}\text { D. Bernardo de Vargas, Milicia, y descripción de } \\
\text { las Indias }\end{array}$ & Madrid & 1599 \\
\hline 103. & Tesillo, guerra de Chile & Madrid & 1647 \\
\hline 104. & Exequias de la Reyna Margarita en Perú & Lima & 1612 \\
\hline 105. & Exequias de la Reyna Margarita en Perú & Lima & 1612 \\
\hline 106. & $\begin{array}{l}\text { Memorial de noticias sacras, y Reales del Imperio } \\
\text { de las Indias Occidentales, por Iuan Díaz de la } \\
\text { Calle }\end{array}$ & Madrid & 1646 \\
\hline 107. & $\begin{array}{l}\text { Chrónica de la Prouincia de Mechoacan, de } \\
\text { Agustinos, por Fr. Iuan de la Puente }\end{array}$ & México & 1624 \\
\hline 108. & $\begin{array}{l}\text { Historia de la destruyción de las Indias, por D. } \\
\text { Bartolomé de las Casas, Hispano, Itálico }\end{array}$ & Venecia & 1630 \\
\hline 109. & $\begin{array}{l}\text { Vida de Don Toribio Alfonso Mogrouejo, } \\
\text { Arçobispo de Lima, por Antonio de León }\end{array}$ & Madrid & 1653 \\
\hline 110. & $\begin{array}{l}\text { Vida del Doctor Don Bernardino de Aluansa, } \\
\text { Arçobispo de Santa Fe, por Don Pedro de Solís }\end{array}$ & Lima & 1646 \\
\hline 111. & $\begin{array}{l}\text { Memorial del Nueuo Mundo, Perú, y Lima, por } \\
\text { Fray Buenauentura de Salinas }\end{array}$ & Lima & 1630 \\
\hline 112. & $\begin{array}{l}\text { Memorial del Nueuo Mundo, Perú, y Lima, por } \\
\text { Fray Buenauentura de Salinas }\end{array}$ & Lima & 1630 \\
\hline 113. & $\begin{array}{l}\text { Antigüedad del linage de vera, por Francisco de } \\
\text { la Puente }\end{array}$ & Lima & 1635 \\
\hline 114. & $\begin{array}{l}\text { Relación del Gouernador Aluar Núñez, de dos } \\
\text { viages de las Indias }\end{array}$ & Valladolid & 1555 \\
\hline 115. & $\begin{array}{l}\text { Descripción del Reyno de Chile, por Fray } \\
\text { Francisco Ponce }\end{array}$ & & \\
\hline
\end{tabular}




\begin{tabular}{|c|c|c|c|}
\hline 116. & $\begin{array}{l}\text { Discursos sobre la Centinela del Reyno de Chile, } \\
\text { de Don Andrés Méndez }\end{array}$ & Lima & 1641 \\
\hline 117. & $\begin{array}{l}\text { Catálogo de Varones de virtud de la Compañía, } \\
\text { en Perú }\end{array}$ & Sevilla & 1632 \\
\hline 118. & $\begin{array}{l}\text { Discursos sobre la Centinela del Reyno de Chile, } \\
\text { de Don Andrés Méndez }\end{array}$ & Lima & 1641 \\
\hline 119. & $\begin{array}{l}\text { Sucessos de las islas Filipinas, por Antonio de } \\
\text { Morga }\end{array}$ & México & 1609 \\
\hline 120. & $\begin{array}{l}\text { Antigüedad de la lengua Vascongada, por Baltasar } \\
\text { de Echaue }\end{array}$ & México & 1607 \\
\hline 121. & $\begin{array}{l}\text { Antigüedad del linage de Vera, por D. Francisco } \\
\text { de la Puente }\end{array}$ & Lima & 1635 \\
\hline 122 & $\begin{array}{l}\text { Nueuo descubrimiento del gran Río de las } \\
\text { Amazonas, año de } 1639 \text { por el Padre Christóual } \\
\text { de Acuña }\end{array}$ & Madrid & 1641 \\
\hline 123. & $\begin{array}{l}\text { Relación del martirio de unos jesuitas en el } \\
\text { Paraguay }\end{array}$ & & 1628 \\
\hline 124. & Hugo Groth, de Origine gentis, Americanae & Amstelod & 1643 \\
\hline 125. & De rebus Iaponicis, \& Peruanis Epistolae recentes & Amberes & 1605 \\
\hline 126. & $\begin{array}{l}\text { Historia trágica de don Enrique Castro en Chile, } \\
\text { por don Francisco Loubayssin }\end{array}$ & París & 1617 \\
\hline 127. & Historia de las Indias, de Gomara, 2 parte & Amberes & 1554 \\
\hline 128. & $\begin{array}{l}\text { Origen de los Indios del nueuo mundo, por Fray } \\
\text { Gregorio García }\end{array}$ & Valencia & 1611 \\
\hline 129. & Chrónica del Perú, de Pedro de Cieza, I p. & Amberes & 1554 \\
\hline 130. & $\begin{array}{l}\text { Historia natural, y moral de Indias, por Ioseph de } \\
\text { Acosta }\end{array}$ & Barcelona & 1591 \\
\hline 131. & Historia del Perú, de Agustín Zárate & Amberes & 1555 \\
\hline 132. & $\begin{array}{l}\text { Viages a Africa, Asia, Indias, de Iuan Mocquet, en } \\
\text { Francés }\end{array}$ & París & 1617 \\
\hline 133. & Iosephus Acosta de natura noui orbis & Salamanca & 1589 \\
\hline 134. & La misma, por el Licenciado Lossa & México & 1613 \\
\hline 135. & $\begin{array}{l}\text { Missiones de la Compañía en Nueua España, por } \\
\text { Andrés Pérez }\end{array}$ & Madrid & 1645 \\
\hline
\end{tabular}




\begin{tabular}{|ll|l|l|}
\hline 136. & $\begin{array}{l}\text { Relación del primer descubrimiento del Río de las } \\
\text { Amazonas }\end{array}$ & \\
\hline 137. & Georgius Hornus, de Origine Gentium, Americar & Hagae & 1652 \\
\hline
\end{tabular}

\section{ANEXO II- OBRAS EDITADAS EN EL NUEVO MUNDO, DE TEMA AMERICANO O NO}

\section{México}

Palafox, Semana Santa, México, 1644.

Palafox, Varón de deseos, México, 1642.

Confessión en lengua mexicana, México, 1565.

Doctrina Christiana, en lengua Mystica, por Fr. Benito Hernández, México, 1568.

Fr. Iuan Baptista, Aduertencias a Confessores, 2 part. México 1600.

Estado de las Filipinas, y sus conueniencias, por D. Gerónimo Bañuelos, México, 1638. Perfecta razón de Estado, contra Polit. Atheit. por Don Iuan Básquez Mayoralgo, México, 1646.

Ordenanças del Obispado de Mechoacan, por D. Fr. Marcos Ramírez, México, 1645.

Ortographía Castellana de Matheo Alemán, México, 1609.

Diálogos Militares de Diego García de Palacio, México, 1585.

Auto de Fe, en México 1649.

Sucessos de las islas Filipinas, por Antonio de Morga, México, 1609.

Antigüedad de la lengua Vascongada, por Baltasar de Echaue, México, 1607.

La misma, por el Licenciado Lossa, México, 1613.

\section{Lima}

D. Iuan María de Gueuara, Corona de la Virgen, Lima,1643.

Symbolo Cathólico Indiano, por Fr. Gerónimo de Ore, Lima, 1598.

Gramática de la lengua del Perú, por Diego Gonçález Holguin, Lima, 1607.

Aduertencias para beber frío de nieue, del Doctor Matías de Porres, Lima, 1621.

Auto de Fe, en Lima, 1639.

Exequias de la Reyna Margarita en Perú, Lima, 1612.

Vida del Doctor Don Bernardino de Aluansa, Arçobispo de Santa Fe, por Don Pedro de Solís, Lima, 1646.

Memorial del Nueuo Mundo, Perú, y Lima, por Fray Buenauentura de Salinas, Lima, 1630. Antigüedad del linage de vera, por Francisco de la Puente, Lima, 1635.

Discursos sobre la Centinela del Reyno de Chile, de Don Andrés Méndez, Lima, 1641. Antigüedad del linage de Vera, por D. Francisco de la Puente, Lima, 1635. 


\section{ANEXO III- GRÁFICOS}
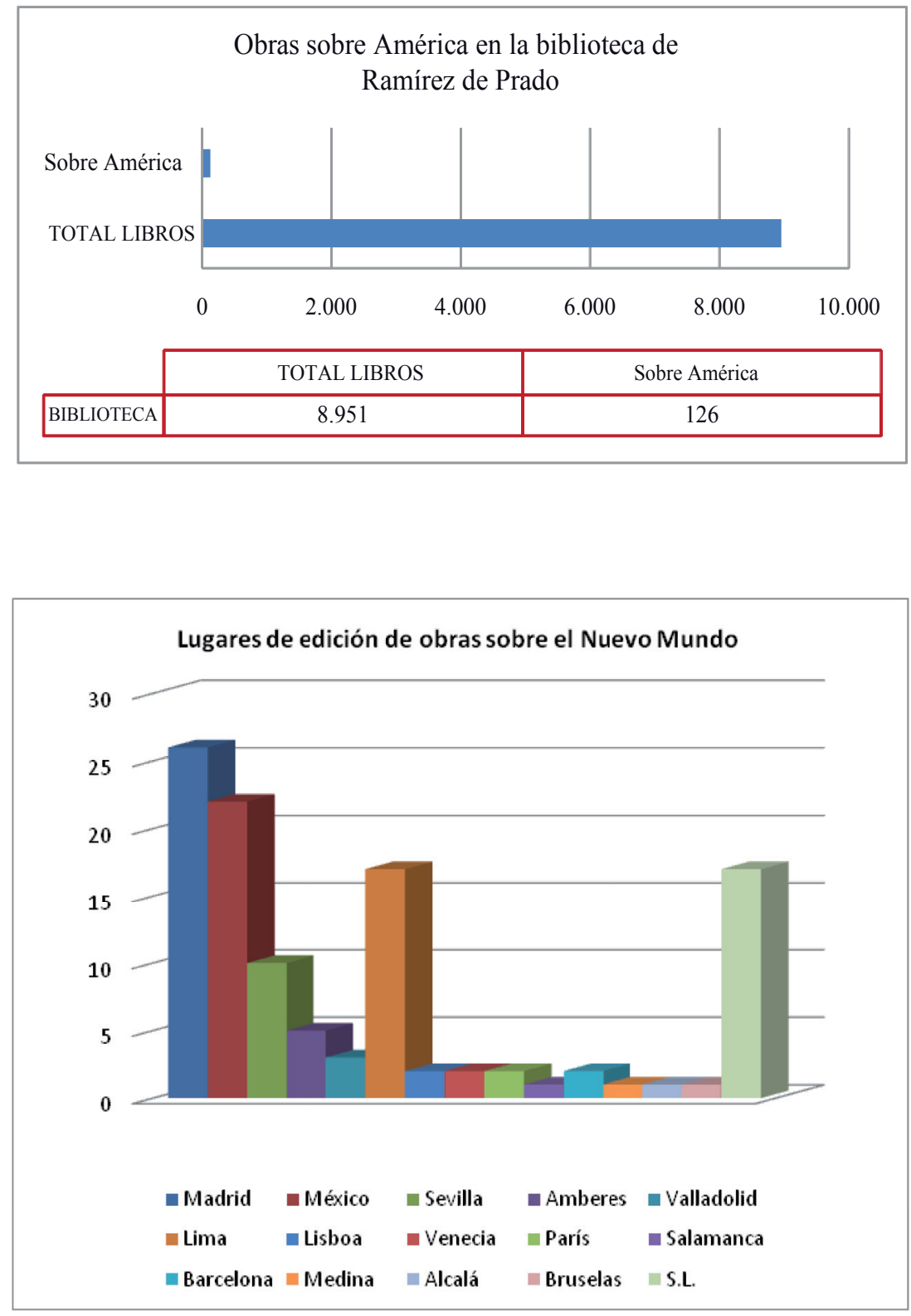


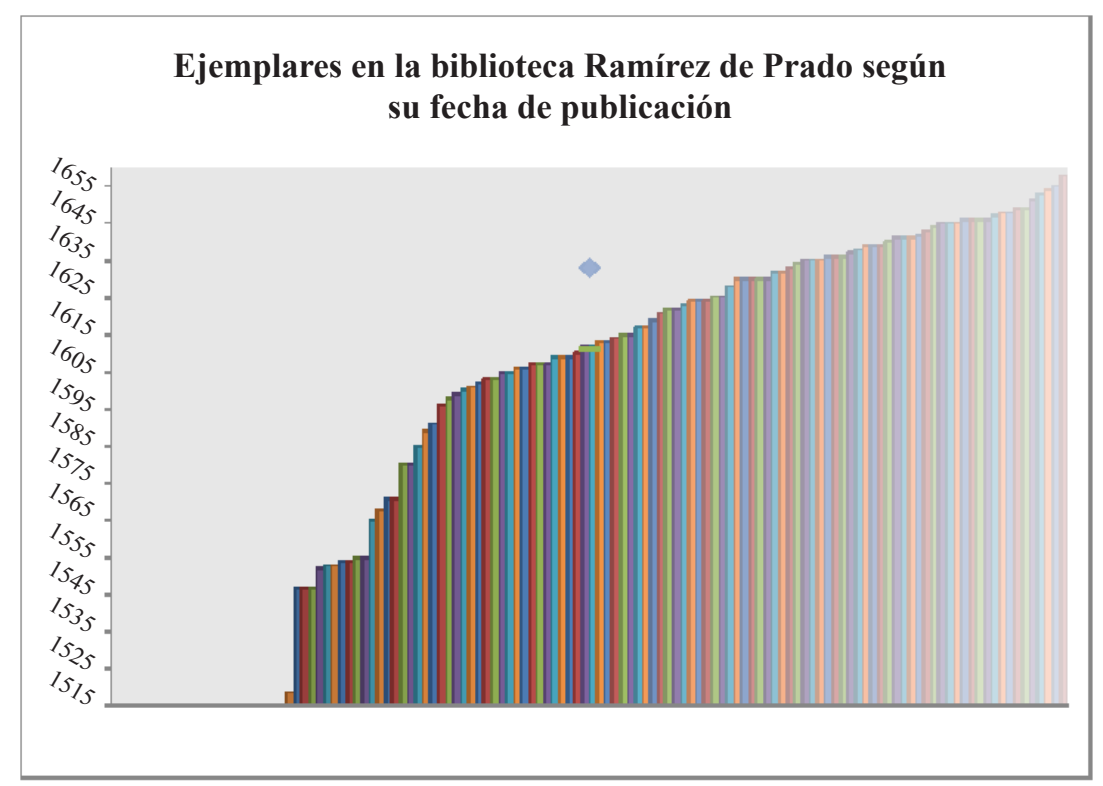




\section{ANEXO IV}

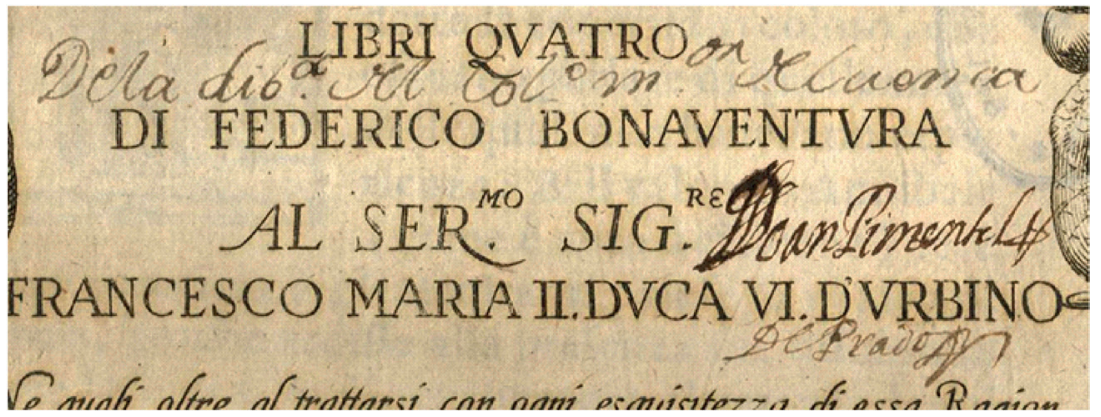

Marca de posesión que aparece en algunos de los libros de Ramírez de Prado. Base de datos de exlibris y marcas de propiedad. Real Biblioteca. $<$ http://encuadernacion.realbiblioteca.es/index.php?p=searchexlibris\&t=identific acion\& $\mathrm{i}=39>$

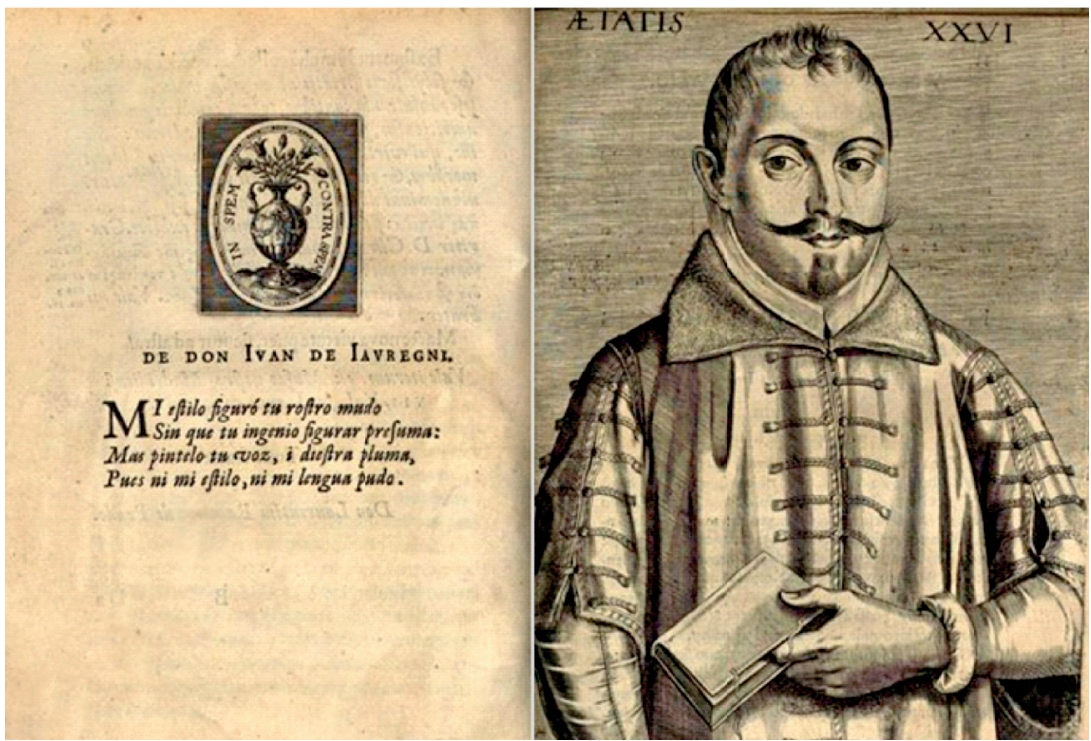

Retrato de don Lorenzo Ramírez de Prado realizado por Juan de Jáuregui, en los preliminares de su obra Pentecontarchus, Antuerpiae, 1612. 


\section{BIBLIOGRAFÍA}

Araoz, Francisco de. De bene disponenda bibliotheca. Madrid, 1631.

Cátedra García, Pedro. Nobleza y lectura en tiempos de Felipe II. La biblioteca de don Alonso Osorio, marqués de Astorga. Valladolid: Junta de Castilla y León, 2002.

Dadson, Trevor. "La presencia del Nuevo Mundo en bibliotecas particulares españolas del Siglo de Oro. II: Inventarios". Las Indias (América) en la literatura del Siglo de Oro: homenaje a Jesús Cañedo. Kassel: Reichemberger, 1992, 213-264.

"La presencia del Nuevo Mundo en bibliotecas particulares españolas del Siglo de Oro". Actas del Primer Congreso Anglo-Hispano. Tomo II, Literatura. Eds. A. Deyermond y R. Penny. Madrid: Castalia, 1993-94, 89-100.

Libros, lectores y lecturas: Estudios sobre Bibliotecas particulares españolas del Siglo de Oro. Madrid: Arco Libros (Instrumenta bibliologica), 1998.

Entrambasaguas, Joaquín de. La biblioteca de Ramírez de Prado. Madrid: CSIC, 1943a. Una familia de ingenios: los Ramírez de Prado. Madrid: CSIC, 1943b.

Fernández Travieso, Carlota y Sagrario López Poza. "IBSO (Inventarios y Bibliotecas del Siglo de Oro). Nueva base de datos en Internet". Etiópicas, Revista de Letras Renacentistas, 7 (2011): 1-30.

Fernández Valladares, Mercedes. "Incunables e impresos góticos españoles de la Biblioteca del Dr. Francisco Guerra". Pecia Complutense: Boletín de la Biblioteca Histórica de la Universidad Complutense de Madrid, 4 (6).

García Hernán, Enrique. Políticos de la monarquía hispánica (1469-1700): ensayo y diccionario. Madrid: Fundación Mapfre Tavera: Fundación Ramón Areces, 2002.

Infantes, Víctor. "Las ausencias en los inventarios de libros y de bibliotecas". Bulletin Hispanique 99 (1997): 281-292.

Lilao Franca, Óscar. "De Córdoba a Madrid: gustos, gastos y libros en la biblioteca de Lorenzo Ramírez de Prado" en La memoria de los libros: estudios sobre la historia del escrito y de la lectura en Europa y América. Bajo la dirección de Pedro M. Cátedra \& María Luisa López Vidriero. Edición al cuidado de María Isabel de Páiz Hernández. Salamanca: Instituto de Historia del libro y la lectura, 2004: 761-780.

López Poza, Sagrario. "La poesía en bibliotecas notables en el siglo XVII". En torno al canon, aproximaciones y estrategias: VII Encuentro Internacional sobre Poesía del Siglo de Oro. Ed. B. López Bueno. Sevilla: Servicio de Publicaciones de la Universidad, 1998, 19-48.

Martínez, Luz Ángela. "El quiebre epistemológico y el surgimiento del nuevo sujeto de conocimiento en la Historia general y natural de las Indias de Gonzalo Fernández de Oviedo". Revista Chilena de Literatura 77 (2010): 235-256.

Rodríguez Moñino, Antonio. Historia de los catálogos de librería españoles (1661-1840): estudio bibliográfico. Madrid, 1966.

Schäfer, Ernesto. El Consejo Real y Supremo de las Indias. Sevilla. 1935-47, 2 vols.

Simón Díaz, José. "Los traductores españoles de Malvezzi”. Revista de literatura 55-56 (1965): 87-93. 
Solís de los Santos, José. "El humanista extremeño Lorenzo Ramírez de Prado, entre Céspedes y el Brocense". La recepción de las artes clásicas en el siglo XVI. Eds. Eustaquio Sánchez Salor et alii. Cáceres: Universidad de Extremadura, 1996, 669-678. 1997.

El ingenioso bibliólogo don Francisco de Araoz. Sevilla: Servicio de Publicaciones,

Diccionario Biográfico y Bibliográfico del Humanismo Español (Siglo XV-XVII). Madrid: Ediciones Clásicas, 2012.

Valladares de Sotomayor, Antonio. Semanario Erudito, que comprehende varias obras inéditas... Madrid: por don Blas Román, 1789, vol. 3. 